\title{
Chromobacterium violaceum: A Review of an Unexpected Scourge
}

\author{
Bachti Alisjahbana $\mathbb{( D}^{1,2}$ \\ Josephine Debora (D) \\ Evan Susandi iD \\ Guntur Darmawan (iD ${ }^{3}$ \\ 'Internal Medicine Department, Hasan \\ Sadikin Hospital, Faculty of Medicine, \\ Universitas Padjadjaran, Bandung, \\ Indonesia; ${ }^{2}$ Research Center for Care \\ and Control of Infectious Diseases, \\ Universitas Padjadjaran, Bandung, \\ Indonesia; ${ }^{3}$ Department of Internal \\ Medicine, Faculty of Medicine, Krida \\ Wacana Christian University, Jakarta, \\ Indonesia
}

\begin{abstract}
Chromobacterium violaceum is a common environmental bacterium that rarely causes disease in humans but has a high fatality rate if it does. Due to the rarity of the cases, clinicians are often unaware of the rapid progression of $C$. violaceum infection and its unexpected antibiotic resistance pattern, which contribute to the failure of patient management. Our review provides the clinical characteristics, possible sources of exposure, and comorbidities and determines factors associated with survival. We gathered information on 132 cases of $C$. violaceum causing disease in humans published between 1953 and 2020 . Patients were predominantly male with a median age of 17.5, interquartile range (IQR) of 5.0-40.0 years, and a third of them were known to have immune deficiencies or comorbidities. Portals of entry were mainly through a wound in the leg and feet $(28.0 \%)$, the torso $(8.5 \%)$, or hands and arms $(6.8 \%)$. It is not uncommon to acquire infection through unintended contact with contaminated water or dust through the mouth or inhalation. The median incubation period is 4.0 days (IQR 2.0-8.0 days) with a duration of clinical course of 17.5 days (IQR 8.0-30.8 days). The high rate of positive blood cultures (56.1\%) and abscesses in internal organs (36.4\%) shows the significant severity of this disease. Sepsis and Bacteremia were related to mortality with a risk ratio (RR) of 5.20 (95\% CI, 0.831-32.58) and 2.14 (95\% CI, 1.05-4.36), respectively. Appropriate antibiotic use prevented death at a RR 0.33 (95\% CI, 0.21-0.52). Most patients who recovered and survived were treated with aminoglycosides, fluoroquinolones and carbapenems. This review shows the malignant nature of C. violaceum infection and the need for clinicians to be aware and provide prompt source management for patients. Appropriate empiric and targeted antibiotic regiment guided by susceptibility test results is of vital importance.
\end{abstract}

Keywords: bacteremia, antibiotic, sepsis, mortality

\section{Introduction}

Chromobacterium violaceum is a free-living, soil and freshwater gram-negative bacillus found in tropical and subtropical regions. Human infection with this organism is not common; therefore, its presence as a causative agent is mostly overlooked in clinical practice unless a patient presents with severe, rapidly deteriorating sepsis and a remarkable purplish lesion and colonies in culture. ${ }^{1-3}$ C. vioaleceum was regarded as a saprophytic organism and non-pathogenic in humans. Wooley first reported its pathogenic characteristics in 1905, observing septicemia in water buffaloes caused by these bacteria. ${ }^{4,5}$ Later, more observations reported high human mortality with fatal septicaemia and skin lesions as well as internal organ abscesses. These manifestations have been reported from various parts of the world in the subtropic and the tropics, including Indonesia. ${ }^{2,4-12}$ The
Correspondence: Bachti Alisjahbana Research Center for Care and Control of Infectious Diseases, Universitas Padjadjaran, Education Hospital Building, Jl. Prof Eijkman No. 38, Bandung, Indonesia

Tel +6282398415612

Fax +62 222044128

Email b.alisjahbana@gmail.com 
organism has been characterized as an opportunistic pathogen causing severe and fatal manifestations in immunocompromised hosts. ${ }^{2,13-16}$ However, this notion is challenged by other cases reporting fatal and severe clinical manifestations in non-immunocompromised hosts as well. ${ }^{5,17-19}$

The earliest observation of the bacterium was made by French scientists Boisbaudran and Gasser in the 1870s, who found rice flower coloration. ${ }^{20}$ Another independent observation was made by Bergonzini of Modena University, Italy, in 1880, who observed a contaminated flask in his experiments with a deep purple substance that after extraction was insoluble with many solvents. This bacterium was named Chromobacterium violaceum and later record it in the Bergey's Manual of Systematic Bacteriology as $C$ violaceum. ${ }^{20}$ In 1976 , two strains of C. violaceum with different colors of white and violet were isolated in Brazil and it was hypothesized that the violacein protected the bacterium against the sun. ${ }^{21}$ There are nine other species of Chromobacterium genus that have been recognized to date, $C$. subtsugae, C. aquaticum, C. haemolyticum, C. piscinae, C. pseudoviolaceum, C. vaccinii, $C$. amazonense, C. alkanivorans, and C. rhizoryzae. ${ }^{22}$

The purple pigment called violacein, which is expressed by the bacteria, has created great research interests. Violacein is thought to confer the virulence of the bacteria and also to have antibiotic-inhibiting properties. $^{23,24}$ The violet pigment of the bacteria is assumed to be the causative agent of septicemia and fatal infections in humans and animals. ${ }^{25}$ Bacteria with a dark violet color are resistant to various antibiotics, including vancomycin, ampicillin, and linezolid, and susceptible to colistin, oxacillin, gentamicin, norfloxacin, chloramphenicol, and amikacin. ${ }^{26}$ Besides violacein, the bacteria also express metabolites that affect the growth of many grampositive and -negative bacteria as well as produce an immunomodulatory effect. ${ }^{25}$ Interestingly, these characteristics have been utilized to produce antibiotic attreonam. ${ }^{27}$ Microbiologically, C. violaceum has biochemical characteristics similar to those of pseudomonas and aeromonas species, ${ }^{24}$ which are related to the primary multi-drug characteristics that are challenging in treatment. ${ }^{3,22}$

Any part of the human body can serve as an inoculation site, with a traumatic break in the skin serving as the most common port of entry for infection in many reported cases, followed by regional lymphadenopathy, widespread bacteremia and abscess development in the visceral organs. $^{3,5,11,17,28,29}$ The mortality rate of $C$. violaceum infection has been reported to be $60 \%-80 \%$ in disseminated infection, and it was difficult to eradicate in most cases. Our review aimed to describe the clinical characteristics, possible sources of exposure, and comorbidities and to determine the factors that are associated with survival.

\section{Materials and Methods}

We carried out a literature search of published case reports or case series using two journal databases: PubMed and Google Scholar. The following search terms were used for searching relevant observational literature: "Chromobacterium violaceum" AND "infection" AND "Case Report." Exclusion criteria were 1) the report did not contain reported cases, 2) the report was written in a language other than English, 3) suspected case of chromobacterium infection but no culture evidence, 4) study reporting chromobacterium culture other than Chromobacterium violaceum, and 5) no information regarding final outcome of the cases. All reviewers did article selection and assessment. The outcome of the searches is summarized in Figure 1. De Siqueira reported three cases, but we included only one case, and the other two cases were not confirmed by bacterial isolation. ${ }^{30}$ From the 111 studies reviewed, we collected information on 132 cases (Figure 1). Most are single-case reports, ${ }^{1,2,4,5,7-9,11,15-18,28,31-80}$ except Huffam provided four cases, ${ }^{81}$ Hagiya, ${ }^{38}$ Karniyarakkal, ${ }^{82}$ Macher, ${ }^{83} \mathrm{Ma},{ }^{84}$ Tee, ${ }^{85}$ and Teoh $^{18}$ each reported three cases, Al Khalifa, ${ }^{31}$ Banik, ${ }^{86}$ Feldman, ${ }^{36}$ Jitmuang, ${ }^{28}$ Macher, ${ }^{83}$ Ognibene, ${ }^{87}$ Pant ${ }^{88}$ Ponte, ${ }^{89}$ Simo, ${ }^{90}$ Sorensen, ${ }^{91}$ Starr, ${ }^{92}$ Suarez, ${ }^{93}$ and $\mathrm{Ti}^{94}{ }^{94}$ each reported two cases. Of these reports, 28 have been reviewed by Yang et al. ${ }^{95}$ Based on these reports we collected information about demographics, incubation period, predisposing factors, comorbidities, clinical presentations, laboratory and microbiologic data, antimicrobial therapy, clinical course and outcome for analysis.

\section{Definition}

Case report year referred to the time when the paper was published. Sepsis was considered if the patient fulfilled the sepsis definition according to Bone et al (1992) as having two or more of 1) temperature $>38$ or $<36{ }^{\circ} \mathrm{C}, 2$ ) heart rate $>90,3)$ respiratory rate $>20$ and $\mathrm{PaCO} 2<32$, and 4) white blood cell count $>12.000 / \mathrm{mm} 3$, or $<4000$, or $>10 \%$ Immature (band) forms. ${ }^{96}$ The location of the first suspected port of entry was classified as in legs and 


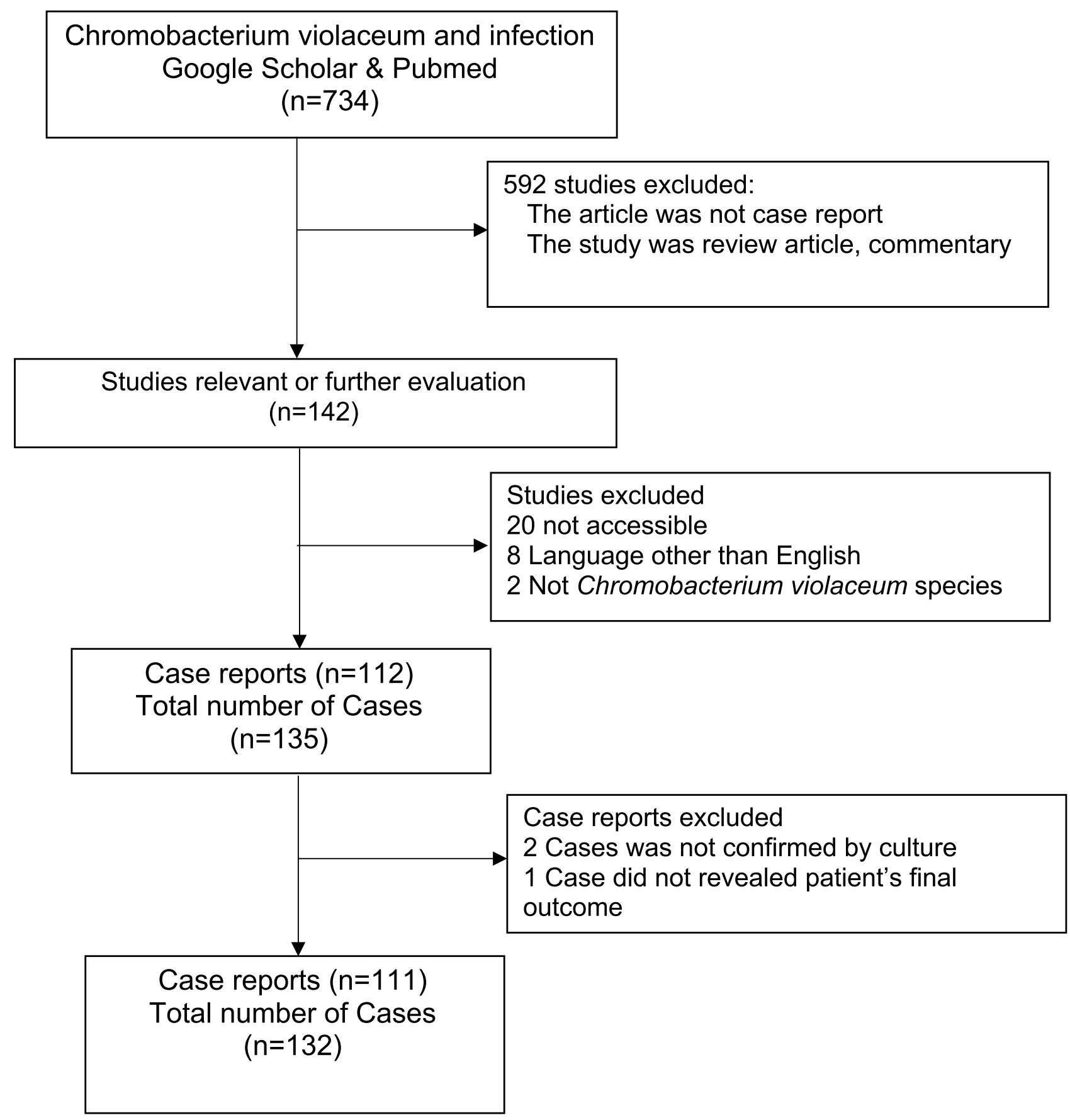

Figure I Enrolment and selection chart of the reviewed studies and cases.

feet, hands and arms, head and neck, neck and trunk, ingestion, inhalation, urinary tract. Skin abscess and cellulitis were defined as any skin infection in the form of pustules, vesicles, ecthyma, or ulcers including lymphadenitis. Comorbidity is defined as having a previously known disease, diagnosed during the course of C. violaceum infection or under other clinical care.
Internal organ abscess was noted if reports contained information about the presence of at least an abscess in the liver, spleen, lung, brain or other organ based on imaging or post-mortem studies. The clinical course was defined as the interval from the onset of symptoms to death or discharge from hospital. A patient was considered to have a particular exposure if the author provided 
information regarding the suspected way of acquiring the infection.

Antimicrobial susceptibility tests were obtained from the reviewed reports, if available. Interpretation of the results followed Clinical and Laboratory Standards Institute guidelines for non-Enterobacteriaceae gramnegatives). ${ }^{97}$ An intermediate reaction was classified as non-susceptible. Antimicrobial therapy was considered appropriate if the treatment regimen included at least one antimicrobial agent described as an active agent against C. violaceum isolates in vitro. It was considered inappropriate if neither drug was sensitive against the isolated strain nor the patient did not receive the specified antimicrobial therapy. Healthcare-associated infection was defined if the infection occurred within hospital care or if the $C$. violaceum infection was related to a medical procedure. The year cut-off of 1990 was used as a reference year because of the general availability of new antibacterial agents, including ciprofloxacin in 2010 because of a previous review made by Yang et al in 2011. . $^{9}$

\section{Statistical Analysis}

We presented data for dichotomous and categorical variables as frequencies and percentages. Continuous variables were presented as mean \pm standard deviation and median and interquartile range (IQR). We used the KolmogorovSmirnov test to identify normal distributions. In the univariate analysis of variables associated with mortality, chi-square and Fisher's exact tests were used for binary variables and risk ratios were calculated. In multivariate analysis, binary logistics regression with backward method was employed to determine the factors most related to mortality outcome. The level of significance $(\alpha)$ was set at 0.05 .

\section{Results}

We have listed and examined case reports from almost all continents, including India and its neighboring countries $(n=31)$, Southeast Asia $(n=20)$, North America $(n=31)$, South America $(n=10)$, Australia and New Zealand $(n=8)$, Africa $(n=8)$, Middle East $(n=3)$ and Europe $(n=6)$. Before 1990, most reports came from North America, but over the years, more reports came from all other countries (Table 1), including areas with cooler climate, such as Japan, ${ }^{64}$ Korea, ${ }^{56}$ China, Switzerland, the Czech Republic and Poland.

Our C. violaceum patients were mostly males from all age groups with a median of 17.5 (IQR 5.0 to 40.0) years old. The highest number of patients was in the younger age group between $0-9$ years old and $20-49$ years old. The incubation period was mostly short (median of 4 days, ranging from 1 to 80 days). Most patients sought medical care because of rapidly developing fever after a localized wound infection. Skin lesions developed into dark or purple colored vesicle abscesses accompanied by necrosis (see Figure 2A). In more than $75 \%$ of cases, routine hematologic examinations showed a pattern of ongoing bacterial infection with a leucocyte count of more than $11.000 / \mathrm{mm}^{3}$ (Table 1). As the disease progressed to sepsis, the leucocyte count gradually increased in parallel with decreasing haemoglobin and thrombocyte values. ${ }^{98}$

Following the initial infection, hematogenic spread occurred, as shown by the high proportion of positive blood culture in these patients (Table 1). The hematogenic dissemination also caused multiple small pustules to occur in other areas of the body. ${ }^{99,100}$ Severe sepsis and septic shock were the most common complications found, often followed by lung involvement with respiratory distress, requiring intensive care intervention. ${ }^{18,24}$ Some patients presented with developing abdominal pain, related abscess formation in the visceral organs, mainly the liver and spleen as shown by imaging studies. Abscess and necrosis also occurred in the lungs following disseminated infection. Skin and soft-tissue infection in the facial area also led to brain abscesses. ${ }^{101}$ Culturing the specimen mainly reveals purple colonies of $C$. violaceum (Figure 2B).

Antibiotic usage was variable, and a large proportion of use was not appropriate as indicated by the antibiotic sensitivity pattern (Table 1). There was a wide range of clinical course duration with a median of 18 days (range 2-264 days). Surviving patients were also affected by relapse of $C$. Violaceum infection, especially those with underlying chronic granulomatous disease. ${ }^{102}$ Elimination of existing visceral abscesses took several weeks to months. ${ }^{81,103}$ As guided by inflammatory markers, antibiotics needed to be taken until abscesses were fully cured. $^{28,103-105}$

These patients acquired $C$. violaceum infection mostly in the community because of environmental exposures. Injuries to the extremities were the most common source (Table 2), mainly due to recreational accidents, ${ }^{33}$ puncture wounds, ${ }^{106}$ or insect bites. ${ }^{100}$ Surprisingly, ingestion or inhalation were not uncommon. Al Khalifa et al reported fatal cases in two boys who acquired infection from a contaminated water storage tank. ${ }^{31}$ Recreational activity in a contaminated lake 
Table I Demographic, Clinical Characteristics, Culture Result and Outcome of I 32 Chromobacterium violaceum Infection Cases Reviewed

\begin{tabular}{|c|c|c|c|}
\hline \multicolumn{2}{|l|}{ Description } & \multirow{4}{*}{$\begin{array}{c}\text { Patients }(\mathbf{n}=\mathbf{1 3 2}) \\
22 \\
47 \\
63\end{array}$} & \multirow{4}{*}{$\begin{array}{c}\% \\
16.7 \\
35.6 \\
47.7\end{array}$} \\
\hline Case report year & Before 1990 & & \\
\hline & Between $1990-2010$ & & \\
\hline & After 2010 & & \\
\hline \multirow[t]{4}{*}{ Age (years) } & $0-9$ & 44 & 33.3 \\
\hline & $10-19$ & 27 & 20.5 \\
\hline & $20-49$ & 37 & 28.0 \\
\hline & $50-$ & 24 & 18.2 \\
\hline Gender $(n=130)$ & Male & 99 & 76.2 \\
\hline Incubation period (days) & Median, IQR (n=49) & 4.0 & $2.0-8.0$ \\
\hline Duration of illness (days) & Median, IQR $(n=124)$ & 5.0 & $2.0-7.0$ \\
\hline \multirow[t]{4}{*}{ Duration of illness } & $0-3$ days & 50 & 37.9 \\
\hline & 4-7 days & 44 & 33.3 \\
\hline & More than 7 days & 30 & 22.7 \\
\hline & Unknown & 8 & 6.1 \\
\hline \multirow[t]{7}{*}{ Clinical Manifestation* } & Skin abscess and cellulitis & 66 & 50 \\
\hline & Sepsis & 102 & 77.3 \\
\hline & Respiratory tract infection & 34 & 25.8 \\
\hline & Prolonged fever & 16 & 12.1 \\
\hline & Abdominal pain & 24 & 18.2 \\
\hline & Dysuria & 9 & 6.8 \\
\hline & Other & 12 & 9.1 \\
\hline White blood cell count (count/mm3) & Median, IQR $(n=|| 2)$ & 14,500 & $9,400-20,800$ \\
\hline \multirow[t]{4}{*}{ White blood cell count (count/mm3) } & $<4000$ & 16 & 14.3 \\
\hline & $4000-11,000$ & 21 & 18.8 \\
\hline & $11,000-20.000$ & 44 & 39.3 \\
\hline & $>20,000$ & 31 & 27.7 \\
\hline \multirow[t]{4}{*}{ Abscesses found in internal organ* } & Liver & 42 & 31.8 \\
\hline & Lung & 22 & 16.7 \\
\hline & Spleen & 12 & 9.1 \\
\hline & Brain & 4 & 3.0 \\
\hline \multirow[t]{6}{*}{ Culture collected from* } & Blood & 74 & 56.1 \\
\hline & Pus & 49 & 37.1 \\
\hline & Biopsy & 19 & 14.4 \\
\hline & Tracheal \& sputum & 9 & 6.8 \\
\hline & Urine & 12 & 9.1 \\
\hline & Other & 6 & 4.5 \\
\hline \multirow[t]{4}{*}{ Colony color $(n=80)$} & Purple & 62 & 77.5 \\
\hline & Purple black/metalic & 7 & 8.8 \\
\hline & Purple translucent & 3 & 3.8 \\
\hline & Translucent/other & 8 & 10 \\
\hline \multirow[t]{3}{*}{ Appropriate antibiotic treatment } & Appropriate & 82 & 62.1 \\
\hline & No & 36 & 27.3 \\
\hline & Unknown & 14 & 10.6 \\
\hline \multirow[t]{4}{*}{ Duration of clinical course } & Within 7 days & 26 & 19.7 \\
\hline & 8 to 21 days & 53 & 40.2 \\
\hline & More than 21 days & 48 & 36.4 \\
\hline & Unknown & 5 & 3.8 \\
\hline \multirow[t]{2}{*}{ Final outcome } & Survived & 50 & 37.9 \\
\hline & Died & 82 & 62.1 \\
\hline
\end{tabular}

Notes: *Any report is calculated as I, no information regarded as none, IQR. interquartile range. 
A

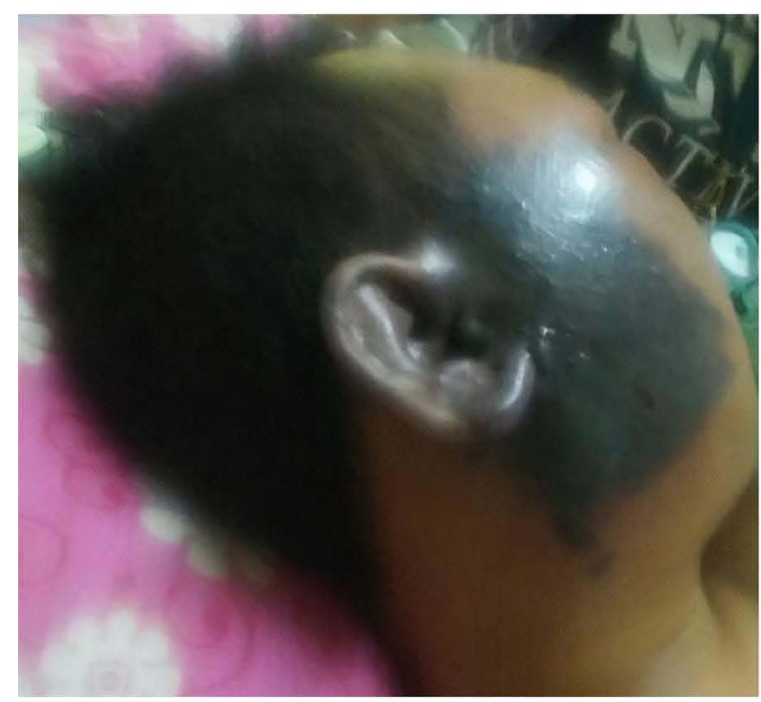

B

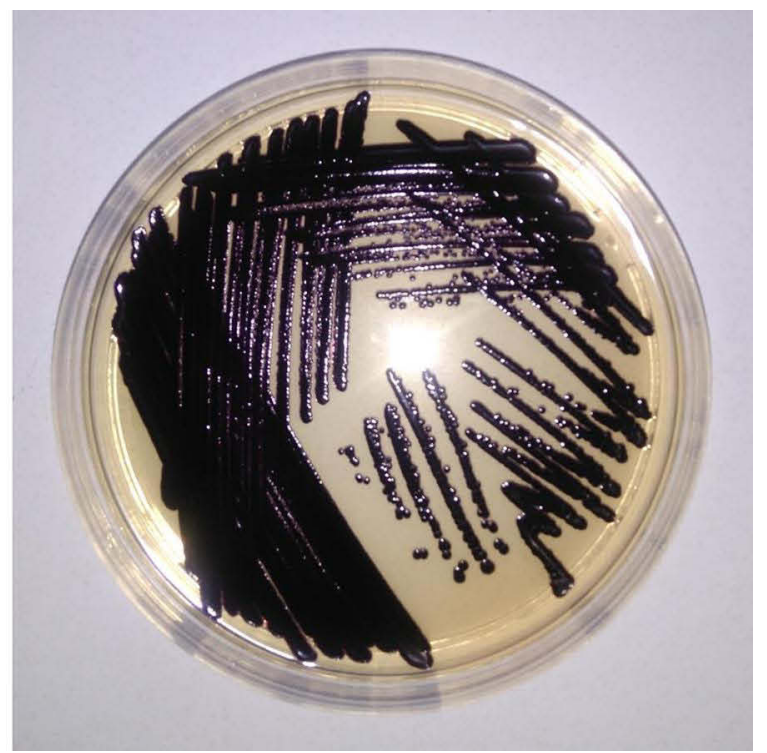

Figure 2 Picture of a patient with black purplish abscess in the right cheek extending to the right ear (A) and Chromobacterium violaceum shown on a culture plate (B). Notes: Reproduced from Darmawan G, Kusumawardhani RY, Alisjahbana B, Fadjari TH. Chromobacterium violaceum: the Deadly Sepsis. Acta Med Indones. 20I8;50(I):80-8I. ${ }^{2}$ Creative Commons Attribution 4.0 International License (https://creativecommons.org/licenses/by/4.0/legalcode).

also affected all three children in a family but without skin injury. ${ }^{30}$ Dust from contaminated ground was also suspected to cause primary pulmonary infection with $C$ violaceum. ${ }^{1,107}$ In fact, five reported successful isolation of $C$. violaceum in the suspected lake, stream and soil sources. A more obscured mode of transmission was through the urinary tract in 12-year-old and 2-month-old children. ${ }^{82,108}$

C. violaceum healthcare-associated infections were also reported (Table 2). These patients were in hospital because of other illnesses or for a routine medical procedure. After a cervical spine surgery, one patient who remained febrile was shown to have $C$. violaceum infection in the femoral venous line. ${ }^{18}$ Cases of urinary tract infection because of recurrent use of a catheter in a chronic kidney disease patients have also been reported. ${ }^{88,109}$ Two cases of infection were probably acquired through the use of a humidified Venturi mask while in transfer to or from an intensive care ward. ${ }^{38}$

Antibiotic susceptibility testing revealed high rate of sensitivity to carbapenems, aminoglycosides, chloramphenicol, quinolones, tetracyclines and trimethoprimsulfamethoxazole. Most first-line treatments for suspected gram-positive contamination of skin injuries, such as penicillin, beta-lactams, and clindamycin, were inactive against C. violaceum (Table 3).

Our serial cases showed that mortality decreased in the latter years (Table 4). It was almost $54.5 \%$ in the years before 1990 and $46.8 \%$ between 1990 and 2010, declining thereafter to $25.4 \%$. Comparison of surviving patients versus fatal cases revealed that five variables were significant for the outcome: case report year, sepsis, bacteremia, appropriate antibiotic use, and duration of clinical course. We include all of these variables except the duration of the clinical course in an adjusted logistic regression model. Different categories of case report year were not associated with higher risk of death, while the other three variables remained important to note. Sepsis and bacteremia were associated with mortality with risk ratio of 5.20 (95\% CI $0.83-32.58)$ and 2.14 (95\% CI, 1.05-4.36), respectively. Appropriate antibiotic use prevented death at risk ratio $0.33(95 \% \mathrm{CI}$, $0.21-0.52)$.

\section{Discussion}

We reviewed cases of $C$. violaceum reported from five continents, showing the universal distribution of this successful species. It is known that $C$. violaceum are distributed in warmer climates of the world between $35^{\circ}$ latitude in the north and south. ${ }^{29}$ The earliest human case reports came from Malaysia, ${ }^{110}$ followed by cases in the southeastern United States among patients with chronic granulomatous disease and in healthy individuals. ${ }^{83,89}$ However, various new cases have been reported from colder regions, such as Japan and Europe. ${ }^{38}$ 
Table 2 Location of Suspected Port of Entry and Comorbidity in Community Acquired and Health Care Associated C. violaceum Infection

\begin{tabular}{|c|c|c|c|c|}
\hline \multirow[b]{2}{*}{ Suspected port d'entrée } & \multicolumn{2}{|c|}{$\begin{array}{l}\text { Community } \\
\text { Acquired }\end{array}$} & \multicolumn{2}{|c|}{$\begin{array}{c}\text { Health Care } \\
\text { Associated }\end{array}$} \\
\hline & & & & \\
\hline Legs and Feet lesion & 33 & 28.0 & 2 & 14.3 \\
\hline Lesion in the torso & 10 & 8.5 & I & 7.1 \\
\hline Head \& Neck lesion & 9 & 7.6 & 0 & - \\
\hline Ingestion & 8 & 6.8 & I & 7.1 \\
\hline Arms \& hand lesion & 8 & 6.8 & I & 7.1 \\
\hline Inhalation/Lungs & 6 & 5.1 & 3 & 21.4 \\
\hline Urinary tract & 4 & 3.4 & 3 & 21.4 \\
\hline Ear & 3 & 2.5 & 1 & 7.1 \\
\hline Eye & 2 & 1.7 & 0 & - \\
\hline Unknown & 35 & 29.7 & 2 & 14.3 \\
\hline Total & 118 & 100.0 & 14 & 100.0 \\
\hline \multicolumn{5}{|l|}{ Comorbidity } \\
\hline None & 29 & 24.6 & 1 & 7.1 \\
\hline Chronic Granulomatous Disease & 14 & 11.9 & 0 & - \\
\hline History of recurrent infection & 7 & 5.9 & 0 & - \\
\hline Diabetes Mellitus & 4 & 3.4 & 1 & 7.1 \\
\hline Hypertension, heart failure/other & 3 & 2.5 & 1 & 7.1 \\
\hline G6PD & 3 & 2.5 & 0 & - \\
\hline Systemic lupus erythematosus & 1 & 0.8 & 0 & - \\
\hline Chronic liver disease & I & 0.8 & 0 & - \\
\hline Chronic lung disease & 0 & - & 2 & 14.3 \\
\hline Hematologic malignancy & 0 & - & 2 & 14.3 \\
\hline Post-surgical intervention & 0 & - & 2 & 14.3 \\
\hline Chronic kidney and urinary tract disease & 0 & - & 2 & 14.3 \\
\hline No information & 56 & 42.4 & 3 & 21.4 \\
\hline Total & 118 & 100.0 & 14 & 100.0 \\
\hline
\end{tabular}

Our C. violaceum infection cases are predominantly in young, male patients. This represents a group of people who are active outdoors and prone to injury. This pattern did not change much compared to case reviews by Yang et al in $2011^{95}$ and the earlier reports in the United States, either among patients with chronic granulomatous disease $^{83}$ or non-immunocompromised individual. ${ }^{89,111}$

Infection with $C$. violaceum often occurred in a recreation or work environment. Contact with water through skin injury or ingestion is one of the most common routes to infection. In the water where $C$. violaceum was found, it was continuously detected through most of the observation time irrespective of human fecal contaminants as represented by E. coli. ${ }^{112}$ The soil is also a natural habitat where $C$. violaceum can be isolated in abundant numbers but not in vegetables or other foods. ${ }^{113}$ It is therefore reasonable to suspect that inhalation of dust outdoors could cause primary pulmonary infection with
Table 3 Antibiotic Susceptibility Pattern

\begin{tabular}{|c|c|c|c|}
\hline Antibiotic & $\begin{array}{l}\text { Tested } \\
(N=\mid 20)\end{array}$ & $\begin{array}{c}\text { Sensitive } \\
\text { (n) }\end{array}$ & $\begin{array}{c}\text { Sensitive } \\
\%\end{array}$ \\
\hline Penicillin & 9 & 0 & 0.0 \\
\hline Ampicillin & 52 & 1 & 1.9 \\
\hline Amoxicillin/clavulanate & 19 & 5 & 26.3 \\
\hline Ampicillin/sulbactam & 8 & 0 & 0.0 \\
\hline Carbenicillin & 7 & 4 & 57.1 \\
\hline Ticarcillin & 8 & 2 & 25.0 \\
\hline Piperacillin & 10 & 6 & 60.0 \\
\hline Mezlocillin & 2 & 1 & 50.0 \\
\hline Tetracycline & 9 & 8 & 88.9 \\
\hline Ticarcillin/clavulanate & 8 & 2 & 25.0 \\
\hline Piperacillin/tazobactam & 41 & 25 & 60.1 \\
\hline $\begin{array}{l}\text { Cephalothin (or cephalexin/ } \\
\text { cefazolin) }\end{array}$ & 33 & 0 & 0.0 \\
\hline Cefuroxime & 26 & 2 & 7.7 \\
\hline Cefoxitin & II & 1 & 9.1 \\
\hline Cefotaxime & 31 & 4 & 12.9 \\
\hline Ceftriaxone & 38 & 5 & 13.2 \\
\hline Ceftazidime & 54 & 10 & 18.5 \\
\hline Cefepime & 36 & 16 & 44.4 \\
\hline Aztreonam & 20 & 7 & 35.0 \\
\hline Imipenem & 57 & 48 & 84,2 \\
\hline Meropenem & 34 & 32 & 94.1 \\
\hline Ertapenem & 9 & 5 & 55.6 \\
\hline Gentamicin & 92 & 79 & 85,9 \\
\hline Netilmicin & 16 & 15 & 93.8 \\
\hline Amikacin & 65 & 51 & 78,5 \\
\hline Tobramycin & 29 & 23 & 79,3 \\
\hline Kanamycin & 13 & 10 & 76.9 \\
\hline Isepamicin & 7 & 6 & 85.7 \\
\hline Clindamycin & 5 & 4 & 80.0 \\
\hline Ciprofloxacin & 77 & 75 & 97.4 \\
\hline Levofloxacin & 22 & 22 & 100 \\
\hline Ofloxacin & II & I I & 100 \\
\hline Norfloxacine & 5 & 5 & 100 \\
\hline Chloramphenicol & 46 & 44 & 95,7 \\
\hline Tetracycline & 21 & 19 & 90,5 \\
\hline Trimethoprim/sulfamethoxazole & 79 & 72 & 91.1 \\
\hline Polymyxin B (or colistin) & 9 & 2 & 22.2 \\
\hline
\end{tabular}

Note:Figures marked in bold indicate a high proportion (>80\%) of $C$. violaceum susceptible to the antibiotic.

C. violaceum. It would also be reasonable to assume that C. violaceum may find an optimal environment in hospital equipment, such as catheters ${ }^{88}$ and Venturi masks. ${ }^{38}$

Chronic granulomatous disease is a well-known predisposing factor to infection by C. violaceum. ${ }^{83}$ Being immunocompromised may underlie other cases, as some reported history of recurrent infection and skin abscess ${ }^{2,81,82}$ and diabetes mellitus. ${ }^{114}$ Chronic granulomatous disease patients are susceptible to infection caused by catalase-producing bacteria such as 
Table 4 Association Risk Factor with Mortality Outcome

\begin{tabular}{|c|c|c|c|c|c|}
\hline Description & $\mathbf{n}$ & Dead $(n=50)$ & Recovered $(n=82)$ & p-value & RR (95\% Cl RR) \\
\hline \multicolumn{6}{|l|}{ Case report time } \\
\hline Before 1990 & 22 & $12(54.5)$ & $10(45.5)$ & & I (ref) \\
\hline From $1990-2010$ & 47 & $22(46.8)$ & $25(53.2)$ & 0.539 & $0.86(0.53-1.40)$ \\
\hline After 2010 & 63 & $16(25.4)$ & $47(74.6)$ & 0.009 & $0.47(0.26-0.82)$ \\
\hline \multicolumn{6}{|l|}{ Age (years) } \\
\hline $0-9$ & 44 & $19(43.2)$ & $25(56.8)$ & & I (ref) \\
\hline $10-19$ & 27 & $9(33.3)$ & $18(66.7)$ & 0.422 & $0.77(0.4 \mathrm{I}-\mathrm{I} .45)$ \\
\hline $20-49$ & 37 & $15(40.5)$ & $22(59.5)$ & 0.811 & $0.94(0.56-1.57)$ \\
\hline $50-$ & 24 & 7 (29.2) & $17(70.8)$ & 0.278 & $0.68(0.33-1.37)$ \\
\hline Gender (Female)* & & $n=49$ & $n=81$ & & \\
\hline Female & 31 & $12(38.7)$ & $19(61.3)$ & & I (ref) \\
\hline Male & 99 & $37(37.4)$ & $62(62.6)$ & 0.965 & $0.97(0.58-1.6 I)$ \\
\hline Comorbidity* & & $n=21$ & $\mathrm{n}=52$ & & \\
\hline No & 30 & $8(26.7)$ & $22(73.3)$ & & I (ref) \\
\hline Yes & 43 & $13(30.2)$ & $30(69.8)$ & 0.742 & I.I3 (0.54-2.39) \\
\hline \multicolumn{6}{|l|}{ Community or healthcare associated } \\
\hline Health care assoc. & 14 & $4(28.6)$ & $10(71.4)$ & & I (ref) \\
\hline Community & 118 & $46(39.0)$ & $72(6 I)$ & 0.478 & $1.36(0.58-3.22)$ \\
\hline \multicolumn{6}{|l|}{ Sepsis } \\
\hline No & 30 & $2(6.7)$ & $28(93.3)$ & & I (ref) \\
\hline Yes & 102 & $48(47.1)$ & $54(52.9)$ & 0.005 & $7.06(1.82-27.35)$ \\
\hline \multicolumn{6}{|l|}{ Bacteraemia } \\
\hline No & 58 & $7(12.1)$ & $51(87.9)$ & & I (ref) \\
\hline Yes & 74 & $43(58.1)$ & $31(4 I .9)$ & $<0.001$ & $4.82(2.34-9.90)$ \\
\hline Abscesses found in internal organ* & & $\mathrm{n}=45$ & $n=73$ & & \\
\hline No & 84 & $31(36.9)$ & $53(63.1)$ & & \\
\hline Yes & 48 & $19(39.6)$ & $29(60.4)$ & 0.759 & $1.07(0.69-1.68)$ \\
\hline Appropriate Antibiotic* & & $n=45$ & $n=73$ & & \\
\hline No & 36 & $30(83.3)$ & $6(16.7)$ & & I (reff) \\
\hline Yes & 82 & $15(18.3)$ & $67(81.7)$ & $<0.001$ & $0.22(0.14-0.35)$ \\
\hline Duration of illness* & & $n=49$ & $\mathrm{n}=75$ & & \\
\hline $0-3$ days & 50 & $21(42.0)$ & $29(58.8)$ & & I (ref) \\
\hline 4-7 days & 44 & $17(38.6)$ & $27(61.4)$ & $0.74 I$ & $0.92(0.56-1.5 \mathrm{I})$ \\
\hline More than 7 days & 30 & II (36.7) & $19(63.3)$ & 0.642 & $0.87(0.49-1.55)$ \\
\hline Duration of clinical course* & & $n=50$ & $n=77$ & & \\
\hline Less 7 days & 26 & $21(80.8)$ & $5(19.2)$ & & I (ref) \\
\hline 8-21 days & 53 & $16(30.2)$ & $37(69.8)$ & $<0.001$ & $0.37(0.24-0.59)$ \\
\hline More than 21 days & 48 & $13(27.1)$ & $35(72.9)$ & $<0.001$ & $0.34(0.20-0.55)$ \\
\hline
\end{tabular}

Note:Rows marked with * indicate lower number $(n)$ subject observed. Figures marked in bold indicate a statistically significant difference $(p<0.05)$.

Abbreviations: RR, risk ratios; Ref, reference group to calculate risk ratios.

C. violaceum because of their inability to carry out adequate oxidative metabolism during phagocytosis. ${ }^{115}$ However, epidemiologically, we still cannot determine the strength of this association because of the small number of reported cases, and many reports did not confirm the immune status of their patients. ${ }^{1,33,37}$ Other than the host immune condition, significant exposure to the bacteria seems to play a role as well. There are at 
least two reports where several healthy children acquired the infection from a shared community source. ${ }^{30,31}$

Once infection is established, $C$. violaceum rapidly spreads locally and through the bloodstream to internal organs, causing multiple abscesses and sepsis. ${ }^{22,110}$ If the mode of entry is inhalation, the patients rapidly develop upper respiratory tract infection followed by severe pneumonia ${ }^{31,35}$ Diarrhea and abdominal pain could be manifestations if $C$. violaceum were transmitted through ingestion ${ }^{116,117}$ The virulence of these bacteria is shown as well by the high proportion of positive blood cultures in the case reports. The success of the invasion by these bacteria partly results from an immunomodulatory effect of secreted substances ${ }^{20}$ as well as a type III secretion system-mediated effect that damages host tissues, including hepatocytes. $^{22}$

The most critical factors for the bacterium's high fatality rate are its severity, unawareness of the clinical characteristics of infection, and inappropriate antibiotic use. With the increasing knowledge of the disease and more antibiotic alternatives, we and others have shown that mortality has decreased. ${ }^{22}$ Initial empirical antibiotic choice is important as C. violaceum are intrinsically resistant to many first-line antibiotics, mainly the penicillin group and beta-lactams. ${ }^{1,23,32,37}$ Although less common, some strains have also been reported to be resistant to imipenem ${ }^{29}$ and aminoglycosides. ${ }^{7,9,16,107}$ Most patients who recovered and survived were treated with aminoglycoside, fluoroquinolone, and carbapenem antibiotic regimens as guided by culture and susceptibility test results. ${ }^{10,14,15,32}$

\section{Conclusion}

C. violaceum is a natural inhabitant of the water and soil and rarely causes disease. However, special care needs to be taken in dealing with patients with ulcers and abscesses and a history of environmental exposure, especially those with the disproportionately rapid development of sepsis, respiratory distress, and visceral pain. The organism shows high rate of susceptibility to aminoglycosides, carbapenems, quinolones, chloramphenicol, tetracyclines, and trimethoprim sulfamethoxazole. Early source control and prompt provision of the appropriate antibiotic regimen guided by culture and susceptibility test results are important in the management of this disease. Proper long-term follow-up care aimed at eliminating remaining bacteria is also vital to prevent relapses.

\section{Disclosure}

The authors report no conflicts of interest for this work.

\section{References}

1. Ang YM. A very rare and rapidly fatal case of Chromobacterium violaceum septicemia. Med J Malaysia. 2004;59(4):535-537.

2. Darmawan G, Kusumawardhani RY, Alisjahbana B, Fadjari TH. Chromobacterium violaceum: the Deadly Sepsis. Acta Med Indones. 2018;50(1):80-81.

3. Fantinatti-Garboggini F, Almeida R, Portillo V, et al. Drug resistance in Chromobacterium violaceum. Genet Mol Res. 2004;3 (1):134-147.

4. Bottieau E, Mukendi D, Kalo J-R, et al. Fatal Chromobacterium violaceum bacteraemia in rural Bandundu, Democratic Republic of the Congo. NMNI. 2015;3:21-23. doi:10.1016/j. nmni.2014.10.007

5. Sharmin S, Jahan AA, Kamal S, Sarker PJ. Fatal Infection Caused by Chromobacterium violaceum: a case report from a tertiary care hospital in Bangladesh. Case Rep Infect Dis. 2019;2019. doi:10.1155/2019/6219295

6. Lin Y, Majumdar SS, Hennessy J, Baird RW. The spectrum of Chromobacterium violaceum infections from a single geographic location. AJTHAB. 2016;94(4):710-716. doi:10.4269/ajtmh.15-0862

7. Pérez JAD, García J, Rodriguez VLA. Sepsis by Chromobacterium violaceum: first case report from Colombia. Braz J Infect Dis. 2007;11(4):441-442. doi:10.1590/s141386702007000400016

8. Karthik R, Pancharatnam P, Balaji V. Fatal Chromobacterium violaceum septicemia in a South Indian adult. $J$ Infect Dev Ctries. 2012;6(10):751-755. doi:10.3855/jidc. 1866

9. Kaufman SC, Ceraso D, Schugurensky A. First case report from Argentina of fatal septicemia caused by Chromobacterium violaceum. J Clin Microbiol. 1986;23(5):956-958. doi:10.1128/ jcm.23.5.956-958.1986

10. Ray P, Sharma J, Marak R, et al. Chromobacterium violaceum septicaemia from north India. Indian J Med Res. 2004;120 (6):523-526.

11. Slesak G, Douangdala P, Inthalad S, et al. Fatal Chromobacterium violaceum septicaemia in northern Laos, a modified oxidase test and post-mortem forensic family G6PD analysis. Ann Clin Microbiol Antimicrob. 2009;8(1):1-5. doi:10.1186/1476-0711-8-24

12. Umadevi S, Kumar S, Stephen S, Joseph N. Chromobacterium violaceum: a potential nosocomial pathogen. Am J Infect Control. 2013;41(4):386. doi:10.1016/j.ajic.2012.05.004

13. Midani S, Rathore MJ. Chromobacterium violaceum infection. South Med J. 1998;91(5):464-466. doi:10.1097/00007611199805000-00011

14. Saboo AR, Vijaykumar R, Save SU, Bavdekar SB. A rare nonfatal presentation of disseminated Chromobacterium violaceum sepsis. J Microbiol Immunol Infect. 2015;48(5):574-577. doi:10.1016/j.jmii.2012.11.002

15. Sirinavin S, Techasaensiri C, Benjaponpitak S, Pornkul R, Vorachit M. Invasive Chromobacterium violaceum Infection in Children: case Report and Review. Pediatr Infect Dis J. 2005;24 (6):559-561. doi:10.1097/01.inf.0000164761.81491.3f

16. Lawrence H, Tucker AJ. Necrotizing External Otitis and Chromobacterium violaceum. Otorhinolaryngol Nova. 2001;11 (6):306-307. doi:10.1159/000068299

17. Ansari S, Paudel P, Gautam K, Shrestha S, Thapa S, Gautam RJ. Chromobacterium violaceum isolated from a wound sepsis: a case study from Nepal. Case Rep Infect Dis. 2015;2015. doi:10.1155/ 2015/181946 
18. Teoh AYB, Hui M, Ngo KY, Wong J, Lee KF, Lai PBS. Fatal septicaemia from Chromobacterium violaceum: case reports and review of the literature. Hong Kong Med J. 2006;12(3):228-231.

19. Bilton BD, Johnson LW. Recurrent nonfatal Chromobacterium violaceum infection in a nonimmunocompromised patient. Infect Med. 2000;17(10):686-689.

20. Durán M, Faljoni-Alario A, Durán N. Chromobacterium violaceum and its important metabolites. Folia Microbiol. 2010;55 (6):535-547. doi:10.1007/s12223-010-0088-4

21. Caldas LR. Photochemistry and photobiology in a virgin land. Photochem Photobiol. 1977;26(1):1-2. doi:10.1111/j.17511097.1977.tb07440.x

22. Batista JH, da Silva Neto J. Chromobacterium violaceum pathogenicity: updates and insights from genome sequencing of novel Chromobacterium species. Front Microbiol. 2017;8:2213. doi:10.3389/fmicb.2017.02213

23. Aldridge KE, Valainis GT, Sanders CV. Comparison of the in vitro activity of ciprofloxacin and 24 other antimicrobial agents against clinical strains of Chromobacterium violaceum. Diagn Microbiol Infect Dis. 1988;10(1):31-39. doi:10.1016/07328893(88)90124-1

24. Kothari V, Sharma S, Padia D. Recent research advances on Chromobacterium violaceum. Asian Pac J Trop Dis. 2017;10 (8):744-752. doi:10.1016/j.apjtm.2017.07.022

25. Durán N, Menck C. Chromobacterium violaceum: a review of pharmacological and industrial perspectives. Crit Rev Microbiol. 2001;27(3):201-222. doi:10.1080/20014091096747

26. Rajalakshmi G, Sankaravadivoo A, Prabhakaran S. Characterization of Chromobacterium violaceum isolated from spoiled vegetables and antibiogram of violacein. $J$ Adv Lab Res Biol. 2011;2(1):18-22.

27. Duma RJ. Aztreonam, the first monobactam. Ann Intern Med. 1987;106(5):766. doi:10.7326/0003-4819-106-5-766

28. Jitmuang A. Human Chromobacterium violaceum infection in Southeast Asia: case reports and literature review. Southeast Asian J Trop Med Public Health. 2008;39(3):452.

29. Moore CC, Lane JE, Stephens JL. Successful Treatment of an Infant with Chromobacterium violaceum Sepsis. Clinical Infectious Diseases. 2001;32(6):e107-e10. doi:10.1086/319356

30. De Siqueira IC, Dias J, Ruf H, et al. Chromobacterium violaceum in siblings, Brazil. Emerg Infect Dis. 2005;11(9):1443. doi:10.3201/eid1109.050278

31. Al Khalifa SM, Al Khaldi T, Alqahtani MM, Al Ansari AM. Two siblings with fatal Chromobacterium violaceum sepsis linked to drinking water. BMJ Case Rep. 2015;2015. doi:10.1136/bcr-2015-210987

32. Bosch F, Badenhorst L, Le Roux J, Louw V. Successful treatment of Chromobacterium violaceum sepsis in South Africa. JMed Microbiol. 2008;57(10):1293-1295. doi:10.1099/jmm.0.2008/001883-0

33. Carter E, Cain K, Rutland B. Chromobacterium violaceum cellulitis and sepsis following cutaneous marine trauma. Cutis. 2008;81(3):269.

34. Chattopadhyay A, Kumar V, Bhat N, Rao P. Chromobacterium violaceum infection: a rare but frequently fatal disease. $J$ Pediatr Surg. 2002;37(1):108-110. doi:10.1053/jpsu.2002.29439

35. Cheong B. A fatal case of pulmonary Chromobacterium violaceum infection in an adult. Med J Malaysia. 2010;65(2):148-149.

36. Feldman RB, Stern GA, Hood C. Chromobacterium violaceum infection of the eye: a report of two cases. Arch Opthalmol. 1984;102(5):711-713. archopht.1984.01040030567019

37. Georghiou PR, O'Kane GM, Siu S, Kemp R. Near-fatal septicaemia with Chromobacterium violaceum. Med J Aust. 1989;150 (12):720-721. doi:10.5694/j.1326-5377.1989.tb136770.x

38. Hagiya H, Murase T, Suzuki M, et al. Chromobacterium violaceum nosocomial pneumonia in two Japanese patients at an intensive care unit. J Infect Chemother. 2014;20(2):139-142. doi:10.1016/j.jiac.2013.10.001
39. Ahmed M, Apte AA, Shukla V, Sarkar D, Shankar H. Chromobacterium violaceum bacteremia in a 2 years old male child. Pediatr Oncall J. 2008;39:452-460. doi:10.7199/ped. oncall.2017.17

40. Anuradha K, Rodrigo P, Karunaratne G, De Silva R, Seneviratne SN, Wickramasinghe V. Chromobacterium violaceum sepsis in an infant with chronic granulomatous disease. J Postgrad Med. 2018;5(1):1-6. doi:10.4038/jpgim.8179

41. Arosio M, Raglio A, Ruggeri M, et al. Chromobacterium violaceum lymphadenitis successfully treated in a Northern Italian hospital. New Microbiol. 2011;34(4):429-432.

42. Ballal M, Kini P, Rajeshwari D, Shivananda P. Chromobacterium violaceum diarrhea. J Pediatr. 2000;67(5):388-389. doi:10.1007/ bf02820697

43. Bansie R, Harkisoen S, Lachman V, Fat ELA, Ramdhani N, van Laar JA. A rare infection in the tropics that is not uncommon in cases of chronic granulomatous disease. Access Microbiol. 2019;1:8. doi:10.1099/acmi.0.000039

44. Blereau R, City M. Septicemia and death caused by Chromobacterium violaceum. South Med J. 1980;73:1093-1094. doi:10.1097/00007611-198008000-00046

45. Bwire GM, Lema N, Makala R, et al. Pediatric Fatal Chromobacterium violaceum in Tanzania: the First Documented Case. SN Compr Clin Med. 2020;2(1):91-94. doi:10.1007/ s42399-019-00177-z

46. Dauphinais R, Robben G. Fatal Infection clue to Chromobacterium violaceum. Am J Clin Pathol. 1968;50 (5):592-597. doi:10.1093/ajcp/50.5.592

47. Dzupova O, Benes J. Serious imported infections: a focus on Chromobacterium violaceum. Bratisl Med J. 2019;120 (10):730-733. doi:10.4149/bll_2019_121

48. Fernandes G, Nascimento A, Borato E, da Silva N, Cunha R, Nascimento T. Chromobacterium Violaceum Sepsis in Minas Gerais. Int Arch Med. 2015;8. doi:10.3823/1691

49. Fernandes M, Luz K, Dantas L, Melo M, Almeida D. Chromobacterium violaceum: a fatal case in the northeast of the Brazil. J Bras Patol Med Lab. 2014;50(4):278-279. doi:10.5935/ 1676-2444.20140027

50. Frawley AA, Powell L, McQuiston JR, Gulvik CA, Bégué RE. Necrotizing Pneumonia Caused by Chromobacterium violaceum: report of a Rare Human Pathogen Causing Disease in an Immunodeficient Child. Am J Trop Med Hyg. 2018;99 (1):164-167. doi:10.4269/ajtmh.18-0060

51. Guo W, Li I, Li X, et al. Sequential Mycoplasma pneumoniae pneumonia and Chromobacterium violaceum skin abscess in a pediatric patient. J Infect Dev Ctries. 2017;11(08):656-661. doi: $10.3855 /$ jidc. 8878

52. Hodge RA. Non-chromogenic Chromobacterium violaceum in a urinary tract infection. Clin Microbiol Newsl. 2002;2(24):15. doi:10.1016/s0196-4399(02)80006-x

53. Jędruszczak A, Węgrzyn-Bąk M, Budzyńska-Nosal R, Maciejewski M, Marczewski K. Sepsis caused by Chromobacterium violaceum-probably the first case in Europe, or Macbeth read anew. Ann Agric Environ Med. 2018;26 (3):508-510. doi:10.26444/aaem/99295

54. Kamat U, Ghodge R. Fatal Case of Chromobacterium violaceum Septicaemia in Goa. JKIMSU. 2021;10(1):111-114.

55. Ke L, An K, Heng S, et al. Paediatric Chromobacterium violaceum in Cambodia: the first documented case. Trop Doc. 2012;42 (3):178-179. doi:10.1258/td.2012.120054

56. Kim M, Lee H, Suh J, Chang B, Cho K. A case of Chromobacterium infection after car accident in Korea. Yonsei Med J. 2005;46(5):700. doi:10.3349/ymj.2005.46.5.700

57. Kumar M. Chromobacterium violaceum: a rare bacterium isolated from a wound over the scalp. IJABMR. 2012;2(1):70. doi:10.4103/2229-516x.96814 
58. Mamlok R, Mamiok V, Mills G, Daeschner III C, Schmalstieg F, Anderson D. Glucose-6-phosphate dehydrogenase deficiency, neutrophil dysfunction and Chromobacterium violaceum sepsis. $J$ Pediatr. 1987;111(6):852-854. doi:10.1016/s0022-3476(87) 80203-2

59. Martinez R, Velludo M, Santos V, Dinamarco P. Chromobacterium violaceum infection in Brazil. A case report. Rev Inst Med Trop. 2000;42(2):111-113. doi:10.1590/s003646652000000200008

60. Mazumder R, Sadique T, Sen D, et al. Agricultural InjuryAssociated Chromobacterium violaceum Infection in a Bangladeshi Farmer. Am J Trop Med Hyg. 2020;103 (3):1039-1042. doi:10.4269/ajtmh.20-0312

61. Midani S, Rathore M. Chromobacterium violaceum infection. South Med J. 1998;91(5):464-466. doi:10.1097/00007611199805000-00011

62. Moretti E, Menozzi F, Elzi L, Lepori M. Chromobacterium violaceum bacteraemia: a new entity in Switzerland. Swiss Med Wkly. 2020;150:1718. doi:10.4414/smw.2020.20220

63. Muharam N, Hussin A, Deris Z. Fatal Case of Chromobacterium violaceum Bacteraemia. Bangladesh J Med Sci. 2019;18 (2):434-436. doi:10.3329/bjms.v18i2.40722

64. Okada M, Inokuchi R, Shinohara K, et al. Chromobacterium haemolyticum-induced bacteremia in a healthy young man BMC Infect Dis. 2013;13(1):1-4. doi:10.1186/1471-2334-13-406

65. Piyasiri D, Samaranayake K, Chinthaka W, Wimalagunarathne N, Rizmy M. Abscess with parotid involvement caused by Chromobacterium violaceum: a rare pathogen. J Postgrad Med. 2014;1. doi:10.4038/jpgim.7333

66. Roberts S, Morris A, Wieser B, McIvor N, Ellis-Pegler R. Chromobacterium violaceum infection of the deep neck tissues in a traveler to Thailand. CID. 1997;25(2):334-335. doi:10.1086/ 516913

67. Salleh S, Zaki Z. Urinary tract infection by Chromobacterium violaceum. Int $J$ Infect Dis. 2020;101:178-179. doi:10.1016/j. ijid.2020.09.479

68. Shao P, Hsueh P, Lu C, Lee P, Lee C, Huang L. Chromobacterium violaceum infection in children: a case of fatal septicemia with nasopharyngeal abscess and literature review. Pediatr Infect Dis J. 2002;21(7):707-709. doi:10.1097/00006454-200207000-00022

69. Shatalov A, Maianski Z. First Case of Chromobacterium violaceum as Urinary Tract Infection Agent in Angola. Open J Med Microbiol. 2019;9(1):37-40. doi:10.4236/ojmm.2019.91005

70. Shenoy S, Baliga S, Wilson G, Kamath N. Chromobacterium violaceum septicemia. Indian O Pediatr. 2002;69(4):363-364. doi:10.1007/bf02723225

71. Shobha K, Bairy I. Prostatitis by Chromobacterium violaceum A Case report. Int $J$ Med Public Health. 2011;1:54-55. doi:10.5530/ijmedph.4.2011.12

72. Thwe PM, Ortiz DA, Wankewicz AL, et al. The Brief Case: recurrent Chromobacterium violaceum Bloodstream Infection in a Glucose-6-Phosphate Dehydrogenase (G6PD)-Deficient Patient with a Severe Neutrophil Defect. J Clin Microbiol. 2020;58(2): e00312-19. doi:10.1128/jcm.00314-19

73. Vincent D, Meghana C, Mohan V, Resmi K. Chromobacterium violaceum causing community-acquired urinary tract infection. Indian J Health Sci Biomed Res. 2017;10:97-99. doi:10.4103/ 2349-5006.198599

74. Zhang P, Li J, Zhang Y-Z, Li X-N. Chromobacterium violaceum infection on lower limb skin: a case report. Medicine. 2021;100 (6):e24696. doi:10.1097/MD.0000000000024696

75. Richard K, Lovvorn J, Oliver S, Ross S, Benner K, Kong M Chromobacterium violaceum sepsis: rethinking conventional therapy to improve outcome. Am J Case Rep. 2015;16:740-744. doi:10.12659/ajcr.894509
76. Tiwari S, Pattanaik S, Beriha S. Nonpigmented strain of Chromobacterium violaceum causing neonatal septicemia: a rare case report. Indian J Pathol Microbiol. 2017;60(3):427-429. doi:10.4103/ijpm.ijpm_479_16

77. Vikram K, Sanghai A, Vohra M, Das V. A case of Chromobacterium violaceum. J Microbiol Infect Dis. 2018;8 (02):76-79.

78. Way S, Sidbury R, Dooms K, Shors A, Qin X, Crane H. Chromobacterium violaceum causing sepsis and focal ulcer in a healthy child. Clin Infect Dis. 2007;15(4):281-283. doi:10.1097/ipc.0b013e31803097d9

79. Wheat R, Zuckerman A, Rantz L. Infection due to Chromobacteria: report of eleven cases. Arch Intern Med. 1951;88(4):461-466. doi:10.1001/archinte.1951.03810100045004

80. Winder M, Ingram D, Vaughan L, Warner H. Chromobacterium violaceum hepatic abscesses in a previously healthy child. Infect Dis Clin Pract. 2012;20(3):219-220. doi:10.1097/ipc.0b01 3e3182424189

81. Huffam S, Nowotny M, Currie B. Chromobacterium violaceum in tropical northern Australia. MJA. 1998;168(7):335-337. doi:10.5694/j.1326-5377.1998.tb138962.x

82. Kaniyarakkal V, Orvankundil S, Lalitha SK, Thazhethekandi R, Thottathil J. Chromobacterium violaceum septicaemia and urinary tract infection: case reports from a tertiary care hospital in South India. Case Rep Infect Dis. 2016;2016. doi:10.1155/2016/ 6795743

83. Macher AM, Casale TB, Fauci AS. Chronic granulomatous disease of childhood and Chromobacterium violaceum infections in the southeastern United States. Ann Intern Med. 1982;97 (1):51-54. doi:10.7326/0003-4819-97-1-51

84. Ma T, Shi W, Cheng J, et al. Chromobacterium violaceum infection in China: three case reports and literature reviews. Afr J Microbiol Res. 2011;5(20):3096-3102. doi:10.5897/ajmr11.623

85. Tee H, Francis A, How S. Chromobacterium violaceum infection. $\mathrm{Br} \quad J \quad$ Hosp Med. 2006;67(4):208-209. doi:10.12968/ hmed.2006.67.4.20869

86. Banik A, Sanjeev H, Kumar A, Snehaa K. Chromobacterium violaceum-an unusual pathogen. Perspectives to ponder! Eastern J Medical Sciences. 2018;6-10. doi:10.32677/ ejms.2018.v03.i01.003

87. Ognibene A, Thomas E. Fatal infection due to Chromobacterium violaceum in Vietnam. AJCP. 1970;54(4):607-610. doi:10.1093/ ajcp/54.4.607

88. Pant ND, Acharya SP, Bhandari R, Yadav UN, Saru DB, Sharma M. Bacteremia and urinary tract infection caused by Chromobacterium violaceum: case reports from a tertiary care hospital in Kathmandu, Nepal. J Med Case Rep. 2017;2017:1-4. doi:10.1155/2017/7929671

89. Ponte R, Jenkins SG. Fatal Chromobacterium violaceum infections associated with exposure to stagnant waters. Pediatr Infect Dis $J$. 1992;11(7):583-586. doi:10.1097/00006454-199207000-00013

90. Simo F, Reuman P, Martinez F, Ayoub E. Chromobacterium violaceum as a cause of periorbital cellulitis. Pediatr Infect Dis J. 1984;3(6):561-563. doi:10.1097/00006454-19841100000017

91. Sorensen R, Jacobs M, Shurin S. Chromobacterium violaceum adenitis acquired in the northern United States as a complication of chronic granulomatous disease. Pediatr Infect Dis J. 1985;4 (6):701. doi:10.1097/00006454-198511000-00028

92. Starr A, Cribbett L, Poklepovie J. Chromobacterium violaceum presenting as a surgical emergency. Pediatr Infect Dis J. 1981;74 (9):1137-1139. doi:10.1097/00006454-198511000-00028

93. Suarez A, Wenokur B, Johnson J, Saravolatz L. Nonfatal chromobacterial sepsis. South Med J. 1986;79(9):1146-1148. doi:10.1097/00007611-198609000-00027 
94. Ti T-Y, Tan WC, Chong AP, Lee E. Nonfatal and fatal infections caused by Chromobacterium violaceum. Clin Infect Dis. 1993;17 (3):505-507. doi:10.1093/clinids/17.3.505

95. Yang C, Li Y. Chromobacterium violaceum infection: a clinical review of an important but neglected infection. J Chin Med Assoc. 2011;74(10):435-441. doi:10.1016/j.jcma.2011.08.013

96. Bone R, Balk R, Cerra F, et al. Definitions for sepsis and organ failure and guidelines for the use of innovative therapies in sepsis. Chest. 1992;101(6):1644-1655. doi:10.1378/chest.101.6.1644

97. Weinstein MP, Lewis IIJS, Bobenchik AM, et al. Performance Standards for Antimicrobial Susceptibility Testing. 27th. Wayne, PA: Clinical and Laboratory Standards Institute; 2017.

98. Baker S, Campbell JI, Stabler R, et al. Fatal wound infection caused by Chromobacterium violaceum in Ho Chi Minh city, Vietnam. J Clin Microbiol. 2008;46(11):3853-3855. doi:10.1 128/jcm.01068-08

99. Brown KL, Stein A, Morrell D. Ecthyma gangrenosum and septic shock syndrome secondary to Chromobacterium violaceum. $\mathrm{J} \mathrm{Am}$ Acad Dermatol. 2006;54(5):S224-S8. doi:10.1016/j.jaad.2005.07.016

100. Lee T, Wright BD. Fulminating chromobacterial septicaemia presenting as respiratory distress syndrome. Thorax. 1981;36 (7):557-559. doi:10.1136/thx.36.7.557

101. Atapattu DN, Jayawickrama DP, Thevanesam V. An unusual bacterium causing a brain abscess. Emerg Infect Dis. 2001;7 (1):159-160. doi:10.3201/eid0701.010127

102. Sureisen M, Choon S, Tai C. Recurrent Chromobacterium violaceum infection in a patient with chronic granulomatous disease. Med J Malaysia. 2008;63(4):346-347.

103. Orsetti A, Markiewicz P, Epstein M, Conceição O, D’Ippolito G, Ribeiro M. Liver abscesses by Chromobacterium violaceum: a case report of a rare disease. OA Case Reports. 2013;28:19-23. doi:10.13172/2052-0077-2-2-426

104. Gao HN, Yuan WX, Yang MF, et al. Clinical significance of C-reactive protein values in antibiotic treatment for pyogenic liver abscess. World J Gastroenterol. 2010;16(38):4871. doi:10.3748/wjg.v16.i38.4871

105. Law ST, Li K. Role of C-reactive protein in response-guided therapy of pyogenic liver abscess. Eur J Gastroenterol Hepatol. 2014;26(2):179-186. doi:10.1097/MEG.0b013e328365a3b7

106. Parajuli NP, Bhetwal A, Ghimire S, et al. Bacteremia caused by a rare pathogen-Chromobacterium violaceum: a case report from Nepal. Int J Gen Med. 2016;9:441-446. doi:10.2147/ijgm.s125183
107. Martinez P, Mattar S. Fatal septicemia caused by Chromobacterium violaceum in a child from Colombia. Rev Inst Med Trop Sao Paulo. 2007;49(6):391-393. doi:10.1590/s003646652007000600011

108. Olalekan A, Itua F, Mutiu B, Egwuatu T, Akinloye O, Iwalokun B. Case Report on Pleural Empyema Thoracis and Urinary Tract Infection Caused by Chromobacterium violaceum from Lagos, Nigeria. J Med Case Rep. 2019;2019:1-5. doi:10.1155/2019/5321484

109. Sachu A, Antony S, Mathew P, et al. Chromobacterium violaceum causing deadly sepsis. Iran J Microbiol. 2020;12(4):364. doi:10.18502/ijm.v12i4.3941

110. Sneath PH, Whelan JP, Bhagwan Singh R, Edwards D. Fatal infection by Chromobacterium violaceum. Lancet. 1953;265 (6780):276-277. doi:10.1016/s0140-6736(53)91132-5

111. Meher-Homji Z, Mangalore RP, Johnson DR. Chromobacterium violaceum infection in chronic granulomatous disease: a case report and review of the literature. JMM Case Rep. 2017;4(1): e005084-e. doi:10.1099/jmmcr.0.005084

112. Byamukama D, Kansiime F, Farnleitner AH, et al. Contrasting occurrence of Chromobacterium violaceum in tropical drinking water springs of Uganda. J Water Health. 2005;3(3):229-238. doi: $10.2166 /$ wh.2005.028

113. Koburger J, May SJA. Isolation of Chromobacterium spp. from foods, soil, and water. Appl Environ Microbiol. 1982;44 (6):1463-1465. doi:10.1128/aem.44.6.1463-1465.1982

114. Yang $\mathrm{CH}$. Nonpigmented Chromobacterium violaceum bacteremic cellulitis after fish bite. J Microbiol Immunol Infect. 2011;44 (5):401-405. doi:10.1016/j.jmii.2010.04.004

115. Goldblatt D, Thrasher A. Chronic granulomatous disease. Clin Exp Immunol. 2000;122(1):1-9. doi:10.1046/j.13652249.2000.01314.x

116. Dromigny J-A, Fall AL, Diouf S, Perrier-Gros-Claude J. Chromobacterium violaceum: a case of diarrhea in Senegal. Pediatr Infect Dis J. 2002;21(6):573-574. doi:10.1097/ 00006454-200206000-00021

117. Swain B, Otta S, Sahu KK, Panda K. Urinary tract infection by Chromobacterium violaceum. J Clin Diagn Res. 2014;8(8):DD01. doi: $10.7860 / J C D R / 2014 / 9230.4703$
International Journal of General Medicine

\section{Publish your work in this journal}

The International Journal of General Medicine is an international, peer-reviewed open-access journal that focuses on general and internal medicine, pathogenesis, epidemiology, diagnosis, monitoring and treatment protocols. The journal is characterized by the rapid reporting of reviews, original research and clinical studies across all disease areas. The manuscript management system is completely online and includes a very quick and fair peer-review system, which is all easy to use. Visit http://www.dovepress.com/ testimonials.php to read real quotes from published authors. 